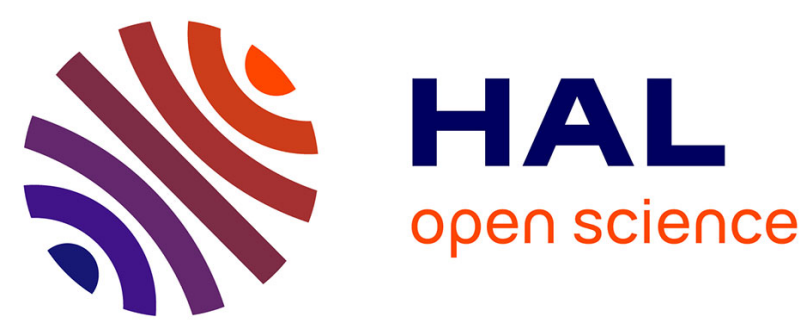

\title{
CAP: Collaborative advanced planning, trade-off between airspace management and optimized flight performance: Demonstration of En-Route reduced airspace congestion through collaborative flight planning
}

Christophe Hurter, Yohann Brenier, Jason Ducas, Estelle Le Guilcher

\section{- To cite this version:}

Christophe Hurter, Yohann Brenier, Jason Ducas, Estelle Le Guilcher. CAP: Collaborative advanced planning, trade-off between airspace management and optimized flight performance: Demonstration of En-Route reduced airspace congestion through collaborative flight planning. DASC 2016, IEEE/AIAA 35th Digital Avionics Systems Conference, Sep 2016, Sacramento, United States. 10.1109/DASC.2016.7777947 . hal-01465908

\section{HAL Id: hal-01465908 \\ https://hal-enac.archives-ouvertes.fr/hal-01465908}

Submitted on 13 Feb 2017

HAL is a multi-disciplinary open access archive for the deposit and dissemination of scientific research documents, whether they are published or not. The documents may come from teaching and research institutions in France or abroad, or from public or private research centers.
L'archive ouverte pluridisciplinaire HAL, est destinée au dépôt et à la diffusion de documents scientifiques de niveau recherche, publiés ou non, émanant des établissements d'enseignement et de recherche français ou étrangers, des laboratoires publics ou privés. 


\title{
CAP: Collaborative Advanced Planning, Trade-off between airspace management and optimized flight performance
}

\author{
Demonstration of En-Route reduced airspace congestion through collaborative flight \\ planning
}

\author{
Christophe Hurter \\ LII \\ ENAC French University for Civil Aviation \\ Toulouse, France \\ christophe.hurter@enac.fr
}

\author{
Yohann Brenier, Jason Ducas, Estelle Le Guilcher \\ DSNA \\ DGAC French Civil Aviation \\ Paris, France \\ yohann.brenier@aviation-civile.gouv.fr
}

\begin{abstract}
High demand of flights on elementary air traffic control sectors results in high delays, extra-fuel burn and $\mathrm{CO} 2$ emissions, and may also lead to safety issues due to the destabilization of the aviation network. This paper presents a new control strategy approach to keep control of the current flight demand in European busiest sectors (Reims, Paris and Marseille sectors). Flow management positions in area control centers suggest to airline operations centers delay-free routes for the most capacity impeding flights within the French airspace. Instead of spreading flight demand over time, this innovative approach aims at spreading the demand in space, relying on local expertise and enhanced collaboration. The trials conducted from July to September 2015 proved to be beneficial for airlines operations with more than 12.000 minutes of delay saved compared to summer 2014 while traffic increased by more than $6 \%$ from 9h to 13h UTC. Following Airport-Collaborative Decision Making, the Collaborative Advanced Planning process paves the way for the En-Route Collaborative Decision Making concept.
\end{abstract}

Keywords-air traffic management, collaboration, en-route, collaborative decision making (CDM), collaborative advanced planning (CAP), operations.

\section{INTRODUCTION}

European Air Traffic Management (ATM) mostly relies on strategic, pre-tactical and tactical traffic flow procedures based on post-operation analysis. Applied measures aim at dynamically find the right balance between airlines' demand and available Air Traffic Control (ATC) capacities: what is called the European Demand and Capacity Balancing (DCB) process.

Applying traffic regulations, hence allocating departure slots and generating delays ( $+31 \%$ in 2015 compared to 2014 in France) is the widespread measure used to face airspace congestion. As traffic demand (Fig. 1) increases $(+2.6 \%$ in 2015 vs 2014 in France), some air traffic control sectors are becoming real bottlenecks for which the implementation of daily regulations can no longer be the sole solution to address airspace congestion and induced critical delays for airlines and passengers. With an estimated price of $\$ 81$ per minute of delay alongside with the recent evolution of European air passenger rights, most of airlines top concern is on-time performance [1]. In the framework of the SESAR business trajectory and European airport CDM concepts, collaboration between airlines and Air Navigation Service Providers (ANSPs) has to be the way forward for smarter and innovative solutions towards seamless skies and enhanced passenger experience.

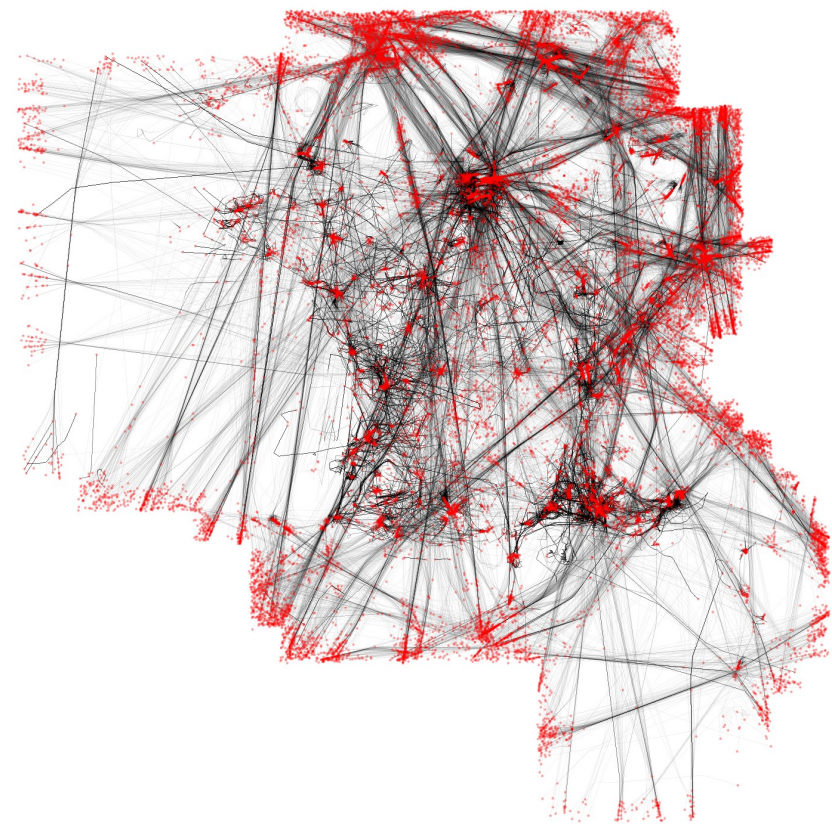

Fig. 1. This image shows the traffic density over France during one day of recorded trajectories (December 2009). The red dots shows the entry points of the trajectory (e.g. take off or landing). 
DSNA, the French ANSP designed a new approach to better distribute the traffic demand according to the control sector capacities available: The Collaborative Advanced Planning (CAP) process. This CAP process allows ATC flow management units to suggest delay-free flight trajectories and/or cruising levels to airlines operations with the objective to prevent control sectors from congestion and induced delays. This collaborative approach introduces a new pre-tactical flowcentric method for Demand and Capacity Balancing in the European Network.

\section{WIDESPREAD EUROPEAN AIR TRAFFIC DEMAND AND CAPACITY BALANCING PROCESS}

Each day, between 20.000 and 35.000 commercial and/or instrument flights fly in the European sky. For each of these flights a flight plan is filed by the airlines' operations (or by the crew). This flight plan contains different information like the aircraft identifier (name of the flight), the type of aircraft, the initial planned route, the expected time of departure, the airspeed, etc.

Each European country has its own airspace structure, i.e. airports, routes, way points, terminal procedures that are used by all airspace users (airlines, pilots...). Fig. 2 explains the different steps that are implemented to ensure smooth operations at hour $\mathrm{H}$ when each flight is in contact (radio or digital connection) with one control center at a time. Usually starting between six and two hours before the departure time:

- a flight plan is filed by the aircraft operator, sent to a European agency that centralizes all the flight plan for Europe (Eurocontrol/IFPS - Integrated Initial Flight Plan Processing System);

- Eurocontrol/ETFMS - Enhanced Tactical Flow Management System - computes the intersection between the route of the flight plans and the airspace structure available in order to provide local Air Navigation Service Providers with the expected traffic load for all control sectors in the European airspace;

- local measures for demand and capacity balancing are decided based on the flight plan demand, the expected traffic load of the sectors, the staff available, and weather forecast. This will determine the local control sector capacity;

- when the traffic load of a sector exceeds its nominal capacity, a regulation is implemented. A regulation usually spreads the initial flight demand over time. When such regulation is put in place, aircraft operators receive a delay message for the flights supposed to enter in the congested sectors.

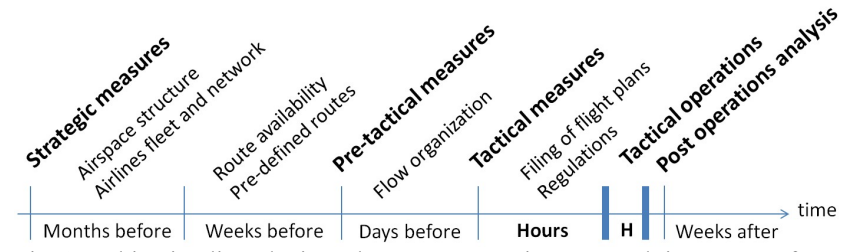

Fig. 2. This timeline depicts the way ATM is managed in Europe from months before operation until post operation analysis. All steps involve a strong interaction between the ANSPs, the Network Manager and the airlines.

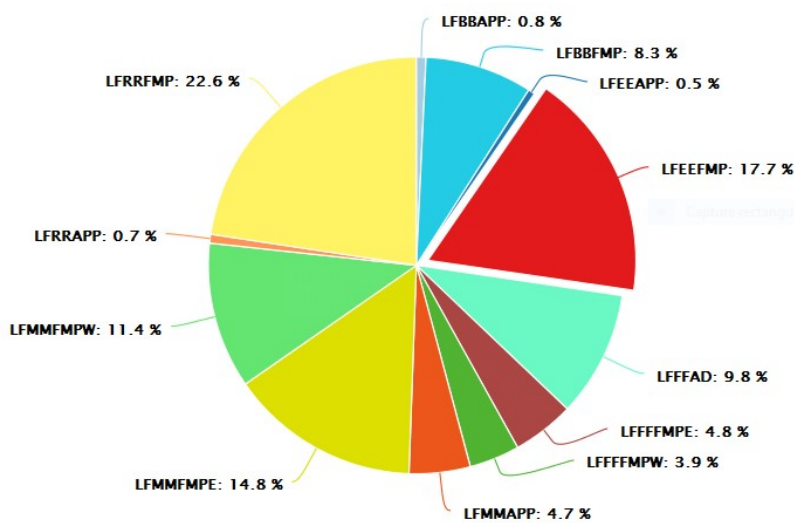

Fig. 3. French ATFM delays in 2014, breakdown by control centers: Bordeaux ACC (LFBB) in blue, Brest ACC (LFRR) in yellow, Paris ACCs (LFFF) in green and brown, Marseille ACC (LFMM) in dark yellow, Reims ACC (LFEE) in Red and approaches.

On a post-operation basis, ATFM (Air Traffic Flow Management) delays generated by these regulations are recorded and used in order to assess the performance of every Area Control Center (ACC) as shown in Fig. 3.

\section{STATE OF THE ART}

Air Traffic Management was investigated with different perspectives by many previous works. Among existing past publications, two major categories can be outlined: Air Traffic Analysis, where traffic is displayed or analyzed with dedicated tools; and Airspace Management and Usage, where the airspace is restructured depending on the traffic analysis, flight trajectories being generated based on the existing airspace structure. These two categories show how this topic is diverse and versatile. This section provides the details of existing tools or algorithms to support air traffic analysis and airspace management. All of these related works helped ENAC and DSNA build the Collaborative Advanced Planning process.

\section{A. Air Traffic Analysis}

The Air Traffic Analysis is achieved with many different tools used to extract data and knowledge from real-time or recorded significant traffic sequences. All of these tools help to better understand the traffic structure and its evolution thanks to different metrics [2] and interaction techniques [3]. Traffic is analyzed with a flow perspective (flow-centric approach); one can thus better compare the recorded trajectories and look into their temporal evolutions [4]. Traffic flows can also be visually analyzed thanks to simplification techniques like the Edge Bundling one [5]. The dynamics of traffic flows can be integrated within a dynamic network [6] using schematization techniques for analysis purposes [7]. Traffic flow dynamics can also be extracted with visual analytic [8] or multiscale techniques [9]. Starting from this flow simplification, control sector configurations can be easily monitored [10]. Finally, this flow analysis can provide unexpected information like meteorological parameters (i.e. wind direction) [11].

Few interaction techniques do exist to manipulate large quantity of aircraft trajectories. FromDady (Fig. 1) shows the first instance of such paradigm [12]. Examples of usages are 
also provided [13]. One of the most promising way to allow this kind of interaction with large dataset relies on the so called Pixel Based Techniques [14].

\section{B. Airspace Management and Usage}

Air Space Management [15] targets many goals: the reduction of flight delay [1], traffic optimization [16] or the satisfaction of the airspace users[17].

Many techniques exist to model and optimize the airspace with automatic systems [18], the use of a predictive model with neural network [19] or meta heuristics [20] and many others relying on local self-organization [21], [22] or introducing dynamics in the decision making process [23], [24], [25]. Some Methods of dynamic air space configuration have been compared [26]. In order to find suitable air space configuration, previous works also investigated a user centered design process [27]. While airspace management aims at optimizing the global ATC capacity, generating optimal flight trajectories relies on several parameters like cost effectiveness [28] or weather conditions [29].

Collaborative processes were also studied in order to better face adverse conditions [30], especially in terminal areas [31].

\section{IMPLICATIONS FOR DESIGN}

\section{A. Scenario of current usages}

The CAP process was designed using walkthrough methods and ecological interface design [32]. Interviews of the different stakeholders were conducted from flow managers in French ACCs to traffic managers and airlines flight planners in airlines operations control centers (OCCs). These interviews were conducted in April 2015.

In the ACCs, the interviews involved representatives of flow manager teams in Reims, Paris and Marseille ACCs (two people at each time). The outcomes of these interviews paved the way for a stronger involvement at the local ATC for which expertise in airline flight planning processes is expected. The need to change less than a dozen flight plan routes is the major enabler in this approach. Finally flow managers of the 3 involved ACCs were on duty from 6 am to $8 \mathrm{pm}$ local time. On the D day, strategies for flow management had been defined four hours ahead of operations based on the flight plan demand. These strategies involved staff availability, initial flight plan demands, available sector configurations, pretactical measures, regulations and tactical workload transfer.

In the airline operation control center, the organization of the tasks related to flight planning changes from one airline to the others. Depending on who is in charge of making the decision for changing a flight plan, traffic managers, senior flight planners, flight planners and chief of operations were met during these walkthroughs in their premises in London, Manchester and Amsterdam. All five airlines are using the same Computerized Flight Plan Service Providers (CFSP) that automatically computes the routes, the optimal flight levels and costs for a dedicated set of flight, aircraft and crew. On time performance is the first objectives of these airlines as it is directly linked to customer satisfaction [17].

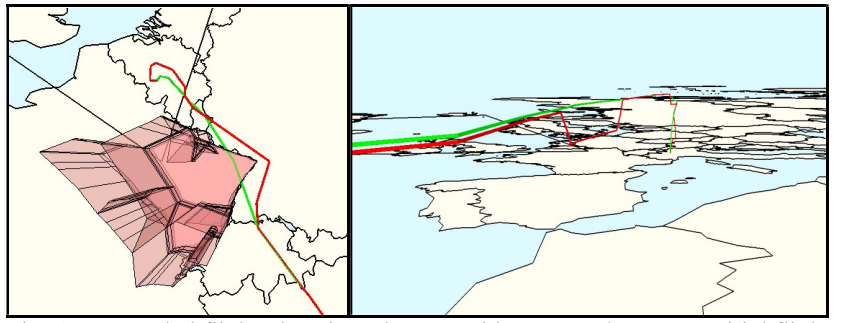

Fig. 4. Amended flight plans in order to avoid congested sectors. Initial flight plan is in green, refiled flight plan is in red.

For each flight, the first flight plan (FPL) is filed and distributed to every ANSP at least six hours before the estimated time of departure. Between the first filing of the FPL and two hours before departure, updates on the route and/or the departure time may be transmitted by airline operations while ANSP are preparing their strategies. If updates on a FPL are communicated later than two hours before departure, the flight is tagged as late updater and subject to more impeding measures. When a flight is delayed because of its flight plan, its route can be modified by the airline operations to try avoiding the congested (and regulated) sectors based on their knowledge of the environment (Fig. 4). The example on the right (Fig. 4) is unrealistic: crew will struggle to descent and then climb again during the cruise phase while it will have highly increased the ATC workload in sectors that are not design to cope with such variable profiles.

\section{B. Observed limits of current usage and improvment perspectives}

These uncontrolled FPL changes may be agreed upon when applied to a limited number of flights. But when these changes affect a lot of flights because of penalizing regulation or favorable jet streams [29], an important part of the initial flight plan demand can shift from initially congested sectors to initially uncongested sectors (Fig. 5). While regulation measures are applied to congested sectors, new regulations might be needed in order to deal with the demand that has shifted: The European network is finally destabilized by such reaction to massively impeding regulations.

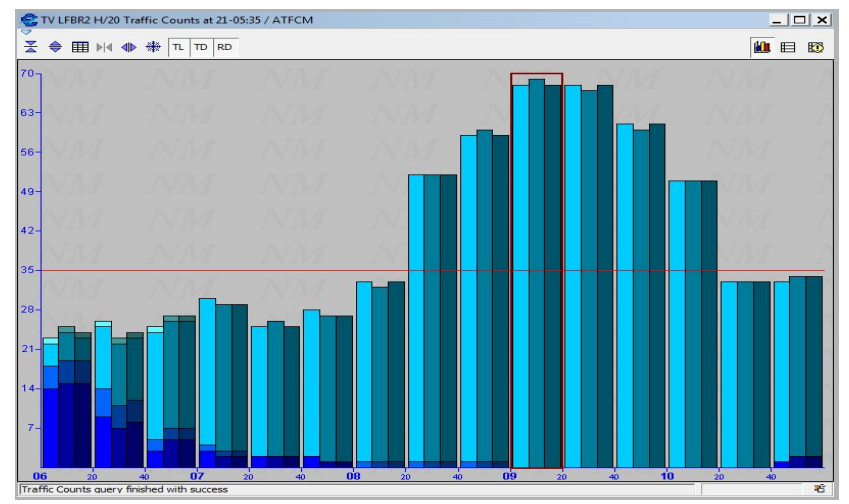

Fig. 5. Flight plan demand spread over three flight levels (FL). Concentration at one FL can be noticed from 07 UTC due to favorable jet streams at this altitude. Red line is the maximum capacity of the sector. This extra demand has to be removed in order to ensure safe operations. 
Local Flow Management Position (FMP) experts have the best knowledge of the traffic structure and are able to identify which flights impede the most on the control sectors capacities. Airline operations are keen to receive any suggestion from a local FMP in order to increase on-time performance while constraining flight performance on a limited number of flights to keep the network stable.

\section{Design requirements}

As a summary of our observations and current activity analysis, we extracted design guidelines to supports users in their flights operations' management. These requirements are summarized below into the following five categories:

Support Asynchronous Communication (AC): since each decision needs to be analyzed beforehand, the operator cannot provide decision making on the fly. This asynchronous communication will leverage the communication flow between operators by providing a history of past events, and using an on the fly chat system.

Collaborative Decision Making (CDM): the need to implement solutions which are compatible with every ACC crossed by any single flight and understandable from an operator, ATC or an airlines perspectives drives us to rely on the CDM principles as already implemented and experienced in the European Airport-CDM concept. These principles mostly rely on the definition of a priority scheme to follow in the decision model for any identified hotspot.

System compatibility with existing regulation process: European demand and capacity balancing processes have been developed for the last 20 years and are run by more than forty different countries. New introduced concept need to rely on existing processes and especially the regulation process since these regulations are the mean to ensure safety in European ATC sectors.

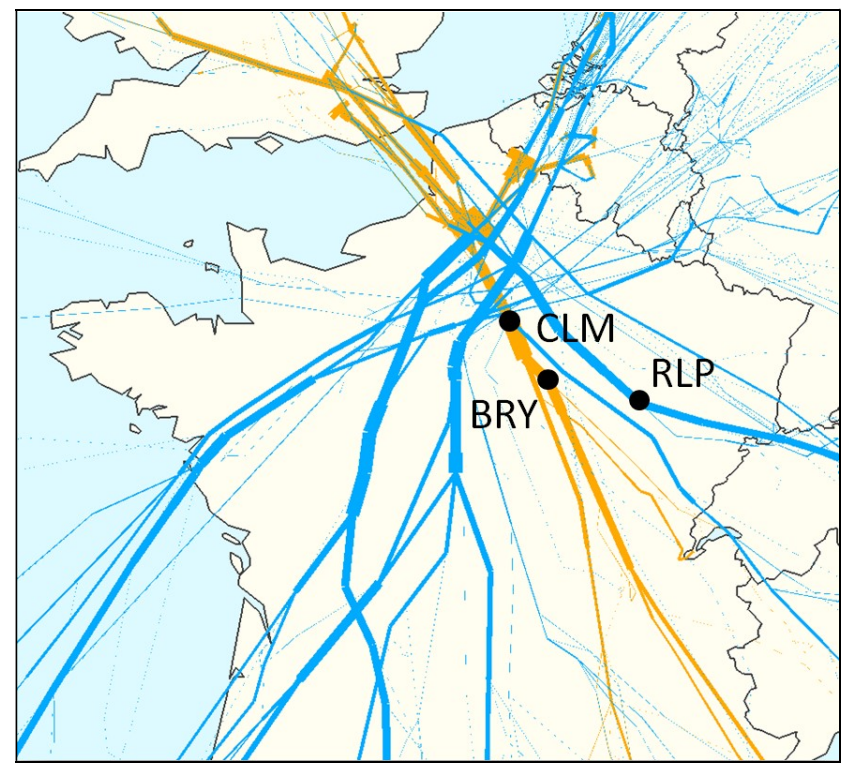

Fig. 6. The different air traffic flows crossing Reims (North-East of France) busiest sectors. In orange, the BRY-CLM flow that first motivated the CAP initiative (more than 200 flights a day).
Compatibility with existing working methods: in all complex systems, solutions that proved their efficiency are difficult to integrate in modern technology. Resistance to change and front line operator acceptance are the more important challenges to deal with. Ensuring the compatibility of the CAP with existing robust methods are key for the acceptance of this new process.

Flexible but Synthetic exchange of Information (FSI): exchanging information about flights mostly rely on computerized flight plan data. Since the main principle of the CAP is to offer to the stakeholders enough flexibility to solve together local hotspots with innovative and highly customized solutions, these operators (with an airline background or an ATC background) need to understand each other. FSI is the common vocabulary to be shared between airlines' operators and ACCs to achieve efficient and simple flight plan refiling.

\section{OUR IMPLEMENTATION: DESIGN OF THE Collaborative AdVANCEd PlanNing}

Based on our design guidelines, the proposed work is entirely operation-oriented. To facilitate its immediate applicability, it is based on flight plan analysis from flow managers and feasibility assessment by airline operators. On the one hand the tradeoff between flight-centric and flowcentric metrics (safety, environment and capacity) provides flow patterns throughout the European network (including flight description, schedules and characteristics). On the other hand, a global picture of the network organization sheds light on the sequenced involvement of each actor: airlines customers and operations departments, flight planning support industries, the European Network Manager, pilots and air traffic controllers. This global knowledge enables to identify the reasons for built up traffic congestions and the involved stakeholders. This process facilitates the collaboration between the right actors at the right time in order to mitigate identified hotspots.

\section{A. Traffic structure}

En-Route congested sectors are dealing with several flows that are crossing each other in the same sector. The more impacting flow in terms of constraints on other flows and induced complexity by the numerous ACCs crossed is the $B R Y-C L M$ axis (Northbound flow from Fig. 6) where the CAP process was initiated.

The BRY-CLM axis sees around 200 flights a day distributed in long haul flights (departing from South Africa), medium haul flight (coming from North Africa, or South of Europe), short haul flow (departing from South of France). These flights are bound for Paris, Belgium or Holland and the United Kingdoms. The measures mentioned above for demand and capacity balancing are used on this flow on a daily basis. 


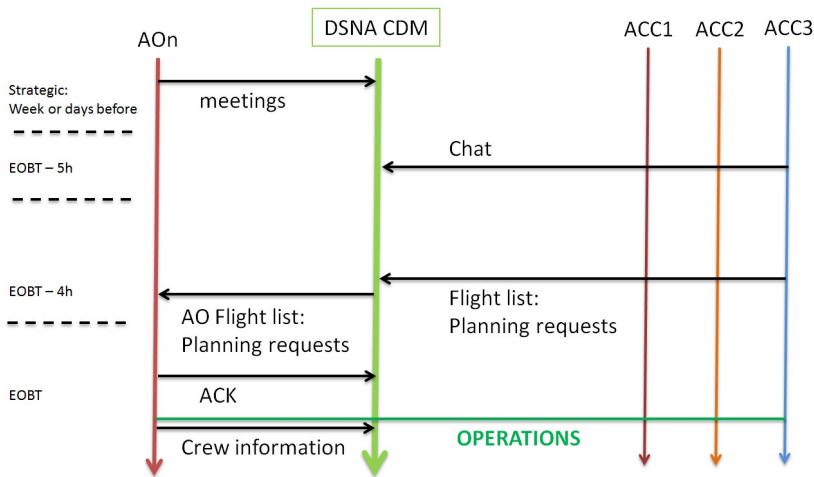

Fig. 7. CAP timing. The process involves strategic meetings and daily collaboration between the stakeholders that starts 5 hours before the potentially impacted flights leave their parking stand: Estimated Off Block Time (EOBT).

\section{B. CAP global design}

The global design of the CAP process relies on mutual understanding of front line operators from ACCs and from OCCs. Constraints of both parties are explained to each parties and a presentation of possible exchange timing is extracted: this drives to Collaborative Decision Making in En-Route airspace management. In order to meet ACCs requirements in terms of flight distribution in the available airspace, the initial flight plan demand has to be known. This demand is available when all flight plans have been first filed, for the shortest flights between 6 and 4 hours before their estimated time of departure. Changes on these flight plans may be achieved between 4 hours and 2 hours before the estimated take off time. These requirements defined the timings of Fig. 7.

In order to support AC and FSI, the drafted interface is divided into free text chat boxes and operational data exchange between airlines OCCs and ACCs as shown Fig. 8.

\section{Asynchronous Communication}

$\mathrm{AC}$ introduces a new paradigm for communication in French operations rooms which is usually done using the phone. To support AC, two basic chat boxes have been offered to the operators during the first trials: a first chat box (Fig. 9) facilitating communication between OCCs and ACCs while the second one is dedicated to DSNA internal negociations.

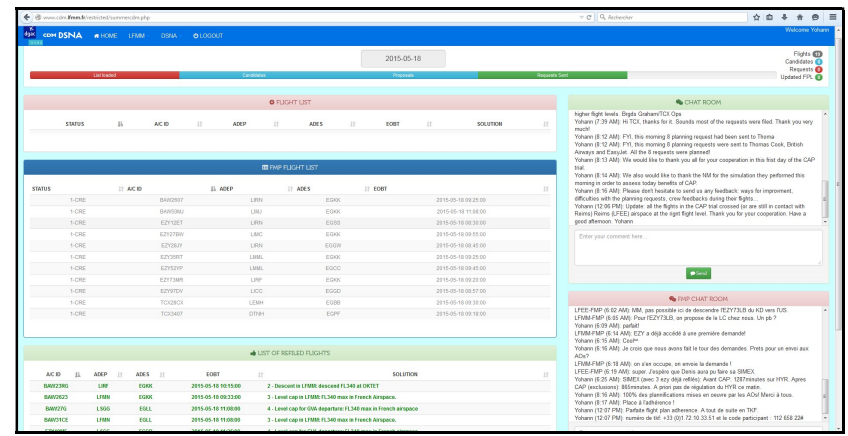

Fig. 8. CAP dsna.fr web-based interface shared in airline operations and ACCs. On the left, shared operational data (flight lists) and on the right free text chat boxes to support AC and FSI.

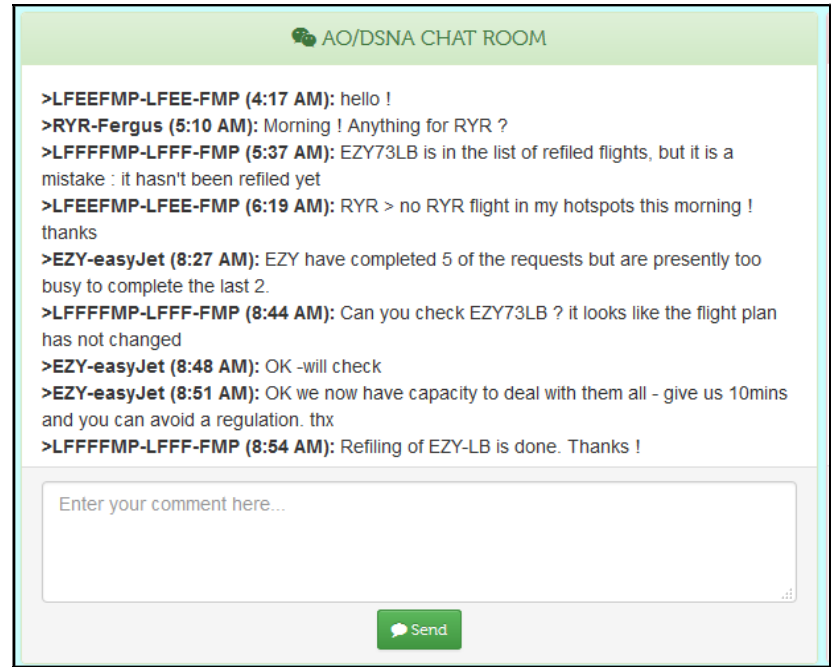

Fig. 9. Extract of the asynchronous communication between participating airlines and French ACCs (July 2015).

This non interruptive communication paradigm favors the acceptance of this new CAP process. First it is not disturbing operators working on their regulation processes during the initial flight plan demand management. Then it favors constructive exchanges which enable mutual understanding within airline OCCs and ACCs.

\section{Flexible but Synthetic exchange of Information}

Fruitful collaboration relies on data that are tactically extracted from operational systems (Fig. 10): name of the flight (A/C ID), airports of departure and arrival (ADEP and ADES), Estimated Off Block Time (EOBT) and current filed route. A set of local planning options are defined in order to spread the demand into available sectors instead of concentrating them into upper regulated sectors (Fig. 11). These options are commonly defined by ACCs and OCCs taking into account their actual feasibility in the planning phases (flight plan) but also by the pilots and air traffic controllers during tactical operations. Criteria like existing waypoints, aircraft performance at considered altitudes, usual workload and induced costs in terms of flight time and extra-fuel burn are investigated. Three types of flight planning requests may be implemented: the full level cap (flight is asked not to fly higher than a specified altitude), the anticipated descend, and the free request (flexibility is offered to the operators). In the common agreed framework, level capping a flight to FL340 instead of flying to FL360 or FL380 induces an extra cost of operations of less than $\$ 250$ and an extra-fuel burn estimated to 100 kilograms of fuel.

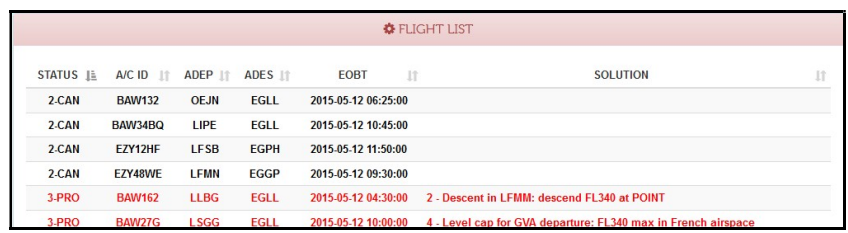

Fig. 10. Flight list shared between OCCs and ACCs. Operational data are completed with specific local constraints to be implemented by the OCCs. 


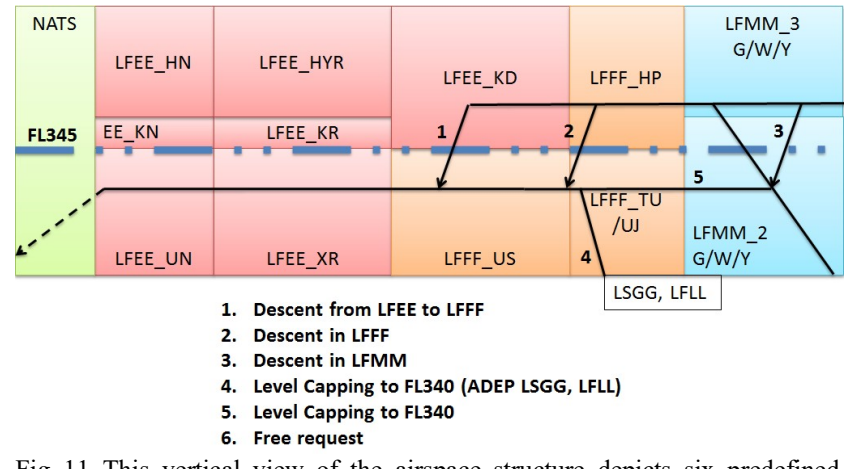

Fig. 11. This vertical view of the airspace structure depicts six predefined flight plan options designed to avoid the HYR and KD sectors.

\section{E. New Scenario of usages: airline OCCs and ACCs additional meetings}

With the five design requirements implemented in the first version of the process (AC, FSI, CDM and compatibilities), the usual working methods and processes can still be run. Whenever real time workload enables running the CAP process, new physical or virtual meetings are schedule to design (Fig. 12), improve or set up tactical collaboration between OCCs and ACCs. Front line operators now integrate daily meeting times through the dedicated web-based interface.

First, the involved ACCs identify a list of hotspots (time and sectors where the demand exceeds the capacity) through the complete BRY-CLM flow. For every hotspot, ACCs identify key flights to remove in order to ease the flow. For each of these key flights, local planning suggestion taken from pre-defined options (Fig. 11) are agreed between ACCs and then communicated to airline OCCs. Then, OCCs assess the feasibility of the route change considering tactical local constraints (fuel, staff availability, crew accessibility...) and inform ACCs on the degree of confidence with which the changes can be achieved. Once a change is done, involved OCCs may confirm that the flight plan has been updated on the web interface while it is transmitted to all stakeholders at the same time.

\section{OPERATIONAL RESULTS OF ACTUAL TRIALS}

The Collaborative Advanced Planning process was tested in real operations according to two different objectives. A first three day trial was organized in May 2015 in order to better calibrate the model of this approach for daily collaboration between airlines and air traffic control units. Then with more actors in the loop, the robustness and consistency of the process was assessed during a summer trial in 2015.

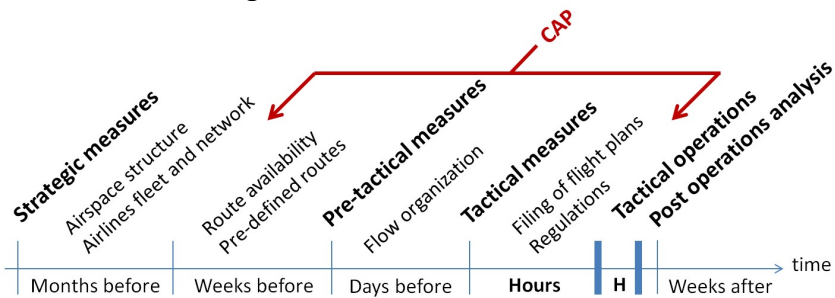

Fig. 12. This timeline depicts the way ATM is managed in Europe with the introduction of the CAP.

\section{A. The investigated flight routes}

To validate our software development, we focused on a specific set of flight routes. These flows were interesting since they had usually been the source of numerous delays (95000 minutes of delay in 2014, part of LFEEFMP delay Fig. 3).

Fig. 13 shows the flows being investigated along with their corresponding density over time.

\section{B. May trial: Testing and Calibration of the model}

Once the modelling of this collaboration was built, the next step consisted in testing and calibration. A first set of flight planning scenarios in the French airspace was defined: cruising level capping, early descent towards a set of destinations and free requests. This procedure relied on large scale live trials involving pilots and air traffic controllers. The first three-day live trial was organized in May 2015 with the $B R Y$-CLM flow, involving three French area control centers and three partner airlines. Under normal conditions and continuously monitored traffic flows, DSNA audited the Collaborative Advanced Planning process when applied by airlines operations, flow managers, pilots and air traffic controllers. The first live trial enabled to save 5.481 minutes of delay over three days by amending 23 flight plans in a flow of more than 200 daily flights. During these three days, the workload in airline operations, cockpits and behind air traffic controller radar screens was monitored in order to better assess the feasibility of such procedure for a summer long implementation in daily operations. An analysis of what actions could be easily achieved from an operational point of view was conducted. Taken into account these feedbacks, new scenarios were defined and implemented two months later with five airlines in the loop.

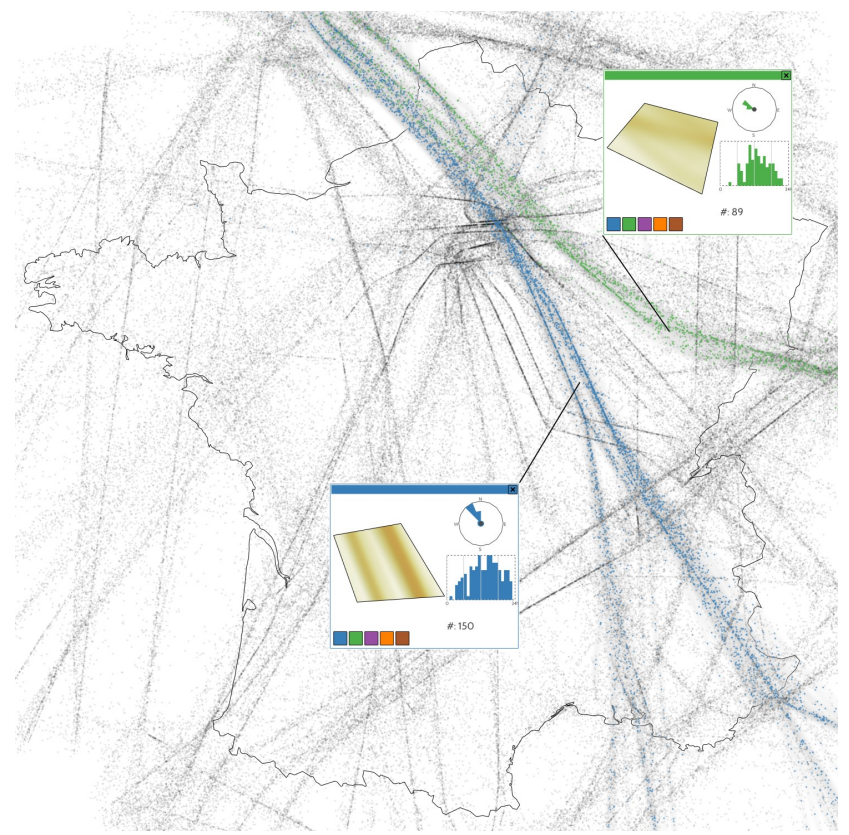

Fig. 13. This figure illustrates the density of flights of the BRY-CLM (blue) and RLP (green) flows. Hourly distribution of these flights can be monitored. Through this point visualization, complexity induced by each flight can be assessed by the flow managers using horizontal and vertical views. 

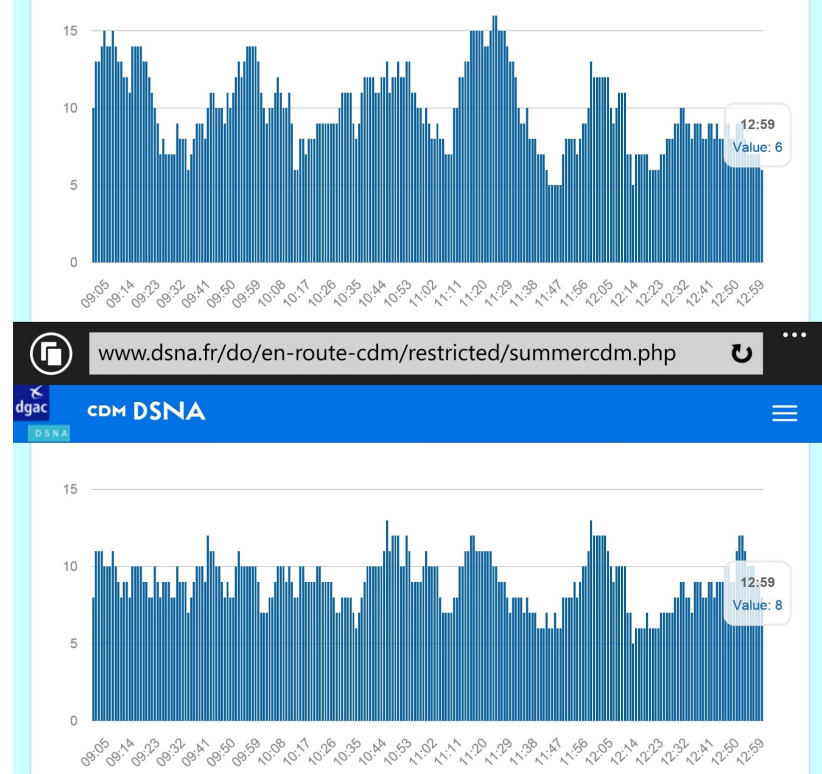

(1)

www.dsna.fr/do/en-route-cdm/restricted/summercdm.php

$\mho$

Fig. 14. Evolution of the flight plan demand in HYR sector while the CAP process is run between all stakesholders. Graph demand at the top represents the initial flight plan demand over time when operators started the process. The one below depicts the demand after flight plans where balanced between upper and lower sectors: traffic peaks are mitigated.

\section{Summer 2015 trial: outcomes, consistency and robustness checks}

In Europe, summer air traffic season starts late April. Traffic increases until mid-July when the shift between business and leisure flight programs operates. Running the CAP process in OCCs and ACCs over a longer period of time from July to September enables to verify its compatibility with the workload and processes that are implemented during high traffic days and weekends. Moreover, a long term assessment of the CAP favors the acceptance of the process by a larger population of FMP staff while requiring a lower involvement of the process design team considering the flexibility of the process.

The summer 2015 trial enabled staff to progressively extend the geographical scope of the process to other flows (RLP, Fig. 6) and challenge the process with unexpected situations like concentration of flights in lower sectors.

From July $7^{\text {th }}$ to September $13^{\text {th }} 2015$, the CAP process was run 62 days over 69. 628 flight plan changes were suggested to the airlines operations. $92 \%$ of these requests were implemented by the airline OCCs. The traffic in the considered sectors (5R) increased by $6 \%$ during summer 2015 compared to summer 2014 while reducing the delay by $52 \%$ during summer 2015 (Fig. 15).

While running the CAP process, the capacity of the ACCs and the OCCs enabled to better estimate the average induced workload on both side of this collaboration. At the same time, it paved the way to more dynamic and safer flight plan demand management. The flight plan demand is now streamlined in the French busiest sectors by acting on less than five FPL for each peak (Fig. 14) rather than delaying hundreds of flights and generating thousands of minutes of delay.

\section{OBSERVATIONS, LESSONS LEARNED AND PERSPECTIVES}

ATC is really pleased with this collaboration, showing that the French ANSP can work closely with the airspace users in order to improve the global performance through innovative and collaborative ATFCM methods.

\section{A. Qualitative outcomes}

Feedback from involved stakeholders was gathered one month after the end of the summer trials.

\section{1) From the ATC point of view:}

The CAP process contributed to a better predictability of the flight plan demand and network stability. DSNA's operators extended the scope of the CAP process to the RLP flow during the summer trial and requested to see the process applied to more flows and more actors.

\section{2) From the airlines point of view:}

"The early notification of workload was appreciated, rather than firefighting when a regulation is applied. It was pleased to be part of the operation, and taking this further. The website is very workable and informative, and airlines look forward to the joint initiative being more extensively used over all of France."

"Less fuel was used on days when the procedure was in place as we were not level capping a high percentage of flights. The benefit was also noticed in the other group airlines as they also saw a more stable French network. One other benefit is now due to this trial we have an excellent dialogue with ATC and believe this will bring a lot of future benefits."

"While the trial increases the workload on our busy Ops department, the benefits could be significant to all airlines flying in the French airspace."

"Communication was fine, simple as we like it. For the future this is the way to go, instead of putting in regulations, an active approach from FMP's is required."

The process was appreciated by the airlines which asked to involve more of them in order to get better situation awareness through the French network.

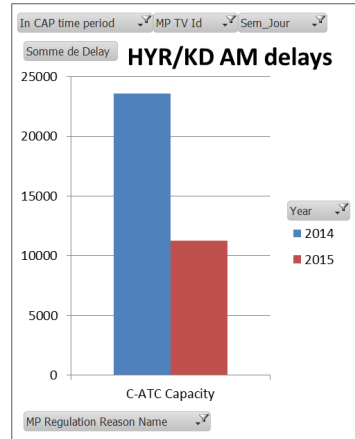

Fig. 15. Morning delay (in minutes) evolution during summer 2015 and summer 2014 in Reims busiest sectors. 


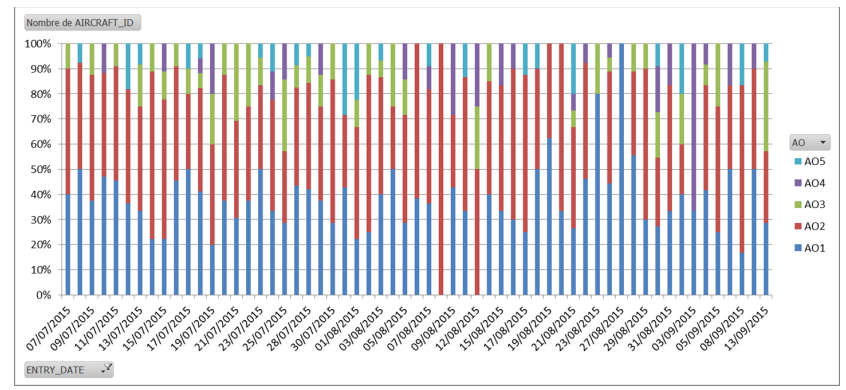

Fig. 16. Daily flight plan change distribution through involved aircraft operators.

\section{B. Lessons learned}

This process demonstrated that daily collaboration between airline operations centers and flow managers in ACCs is feasible and fruitful on a daily basis.

Light was also shed on the need to focus on first line actors' expertise first when trying to improve collaboration in air traffic management processes, rather than defining processes and looking into new support technology.

From an ANSP point of view, it has shown that the need of transparency is essential when it comes to collaboration with several airspace users. During these trials, the participation and CAP involved flights for each airline were monitored and broadcasted to all the other airlines (Fig. 16).

Finally, the more important benefit of the CAP process is the strong improvement of what is called the Common Situation Awareness (CSA) through the European ATM Network. In this way, every involved actor is able to inform other bodies of its current situation and/or participation status as simple as: "busy", "dealing with a flight problem", "dealing with congestion in our sector", "available to help other actors or sometimes competitor airlines".

\section{Perspectives}

The CAP principle proved its efficiency with its implementation on the BRY-CLM flow. Currently different flows are considered as potential "candidates" for a CAP process:

- MANAK-TUPAR: Northbound flow from Spain to the United-Kingdoms;

- EYDD: Southwest bound flow from central Europe to Southwest Europe;

- $\quad$ LFMM 4th layer: optimizing flight distribution of the Westbound and Eastbound main flows in Marseille airspace.

Globalization of the process relies on more airlines, more ACCs to join the initiative within an increasing European air traffic.

At the end of the summer 2015 trial, it was decided to continue playing the process. At the beginning of summer 2016, the CAP process is being run in both MANAK-TUPAR and LFMM scenarios. Three more airlines joined the initiative.

\section{CONCLUSION}

This paper focuses on the design of a new daily Air Traffic Management collaborative process involving ATC actors and airspace users (airlines operations). Already implemented in the French airspace, the Collaborative Advanced Planning (CAP) process enables daily pre-tactical and tactical collaboration between airlines and Air Navigation Service Providers throughout the aviation route network (and not only during adverse events). The effects of Demand and Capacity Balancing are mitigated while meeting the objectives of flightcentric (airline point of view) and flow-centric approaches (ATC point of view): improving flights' on-time performance, reducing ATFM delays in control sectors subject to significant traffic growth. Within the prospect of increasing Common Situation Awareness in Air Traffic Management, this innovative initiative shows that collaboration needs to focus on first line actors' mutual understanding and knowledge while supporting Asynchronous Communication (AC), Collaborative Decision Making (CDM), compatibility with existing working methods and Flexible but Synthetic exchange of Information (FSI) in operational rooms.

This research follows a continuous incremental process. The next steps are first to extend the scope of the Collaborative Advanced Planning process in terms of flows and participation (ATC and airlines) and to better support the decision making steps of this process. In parallel, we will focus on framing the En-Route CDM concept from the gathered bottom-up initiatives like the CAP and support its implementation at a European level from both research and operations perspectives.

\section{ACKNOWLEDGMENT}

Christophe Hurter coordinated the academic research of the CAP project. Yohann Brenier is the DSNA CAP project manager, an idea he supported and coordinated while he was in charge of the DSNA summer 2015 plan. Jason Ducas is in charge of the communication around the CAP project. Estelle Le Guilcher ensured the funding and acceptance of the project.

We would like to acknowledge the cooperation and involvement of all the people who contributed and still contribute to this CAP project: Paris, Marseille, Reims, Brest and Bordeaux flow management units for developing the process and running it on a daily basis, the Network Manager Operations Center at Eurocontrol for providing the delay simulations. Special thanks to Céline Tea, Corinne Papier, Jérôme Dufossez, Marie-Laure Faure, Nicolas Roberto, Stéphane Tchertchian, Thierry Durigneux from DSNA who initiated the process, to Martin Djikzeul from KLM, Duncan Philipp from EasyJet, Melanie Whitehead and Ian Pauls from British Airways, Chis Woodland from Thomas Cook Airlines and Fergus Lawless from Ryanair for joining and their contribution to the initiative.

\section{REFERENCES}

A. J. Cook and G. Tanner, "European airline delay cost reference values," 2011.

D. Gianazza, "Airspace configuration using air traffic complexity metrics," in ATM 2007, 7th USA/Europe Air 
Traffic Management Research and Developpment Seminar, 2007.

[3] C. Hurter, S. Conversy, D. Gianazza, and A. Telea, "Interactive image-based information visualization for aircraft trajectory analysis," Transportation Research Part C: Emerging Technologies, vol. 47, pp. 207-227, 2014.

[4] R. Scheepens, C. Hurter, H. Van De Wetering, and J. J. Van Wijk, "Visualization, selection, and analysis of traffic flows," IEEE transactions on visualization and computer graphics, vol. 22, pp. 379-388, 2016.

[5] C. Hurter, O. Ersoy, and A. Telea, "Graph bundling by kernel density estimation," in Computer Graphics Forum, 2012, pp. 865-874.

[6] C. Hurter, O. Ersoy, S. I. Fabrikant, T. R. Klein, and A. C. Telea, "Bundled visualization of dynamicgraph and trail data," IEEE transactions on visualization and computer graphics, vol. 20, pp. 1141-1157, 2014.

[7] C. Hurter, M. Serrurier, R. Alonso, G. Tabart, and J.-L. Vinot, "An automatic generation of schematic maps to display flight routes for air traffic controllers: structure and color optimization," in Proceedings of the international conference on advanced visual interfaces, 2010, pp. 233240.

[8] G. Andrienko, N. Andrienko, C. Hurter, S. Rinzivillo, and S. Wrobel, "Scalable analysis of movement data for extracting and exploring significant places," IEEE transactions on visualization and computer graphics, vol. 19, pp. 1078-1094, 2013.

[9] T. Klein, M. Van Der Zwan, and A. Telea, "Dynamic multiscale visualization of flight data," in Computer Vision Theory and Applications (VISAPP), 2014 International Conference on, 2014, pp. 104-114.

[10] A. Marzuoli, C. Hurter, and E. Feron, "Data visualization techniques for airspace flow modeling," in Intelligent Data Understanding (CIDU), 2012 Conference on, 2012, pp. 7986.

[11] C. Hurter, R. Alligier, D. Gianazza, S. Puechmorel, G. Andrienko, and N. Andrienko, "Wind parameters extraction from aircraft trajectories," Computers, Environment and Urban Systems, vol. 47, pp. 28-43, 2014.

[12] C. Hurter, B. Tissoires, and S. Conversy, "FromDaDy: Spreading data across views to support iterative exploration of aircraft trajectories," IEEE TVCG, vol. 15, pp. 10171024, 2009.

[13] C. Hurter, G. Andrienko, N. Andrienko, R. H. Guting, and M. Sakr, "Air traffic analysis," Mobility data: modeling, management, and understanding, pp. pp 240-258, 2013.

[14] C. Hurter, "Image-Based Visualization: Interactive Multidimensional Data Exploration," Synthesis Lectures on Visualization, vol. 3, pp. 1-127, 2015.

[15] G. Lulli and A. Odoni, "The European air traffic flow management problem," Transportation Science, vol. 41, pp. 431-443, 2007.

[16] D. Gianazza and K. Guittet, "Selection and evaluation of air traffic complexity metrics," in 2006 ieee/aiaa $25 \mathrm{TH}$ Digital Avionics Systems Conference, 2006, pp. 1-12.

[17] M. Dresner and K. Xu, "Customer service, customer satisfaction, and corporate perfo," Journal of Business Logistics, vol. 16, p. 23, 1995.
[18] P. Flener and J. Pearson, "Automatic airspace sectorisation: A survey," arXiv preprint arXiv:1311.0653, 2013.

[19] D. Gianazza, "Forecasting workload and airspace configuration with neural networks and tree search methods," Artificial intelligence, vol. 174, pp. 530-549, 2010.

[20] N. Durand, D. Gianazza, J.-M. Alliot, and J.-B. Gotteland, Metaheuristics for Air Traffic Management vol. 2: John Wiley \& Sons, 2016

[21] T. S. Hand, "Self-organized traffic flows: a sequential conflict resolution approach," 2013.

[22] I. Simaiakis, H. Khadilkar, H. Balakrishnan, T. G. Reynolds, and R. J. Hansman, "Demonstration of reduced airport congestion through pushback rate control," Transportation Research Part A: Policy and Practice, vol. 66, pp. 251-267, 2014.

[23] A. Klein, P. Kopardekar, M. D. Rodgers, and H. Kaing, "Airspace playbook: Dynamic airspace reallocation coordinated with the national severe weather playbook," in Proceedings of the 7th AIAA Aviation Technology, Integration and Operations Conference, 2007.

[24] R. Ehrmanntraut and S. McMillan, "Airspace design process for dynamic sectorisation," in 2007 IEEE/AIAA 26th Digital Avionics Systems Conference, 2007, pp. 3. D. 2-1-3. D. 2-9.

[25] M. Bloem and P. Gupta, "Configuring airspace sectors with approximate dynamic programming," 2010.

[26] S. Zelinski and C. F. Lai, "Comparing methods for dynamic airspace configuration," in Digital Avionics Systems Conference (DASC), 2011 IEEE/AIAA 30th, 2011, pp. 3A11-3A1-13.

[27] N. Saporito, C. Hurter, D. Gianazza, and G. Beboux, "A participatory design for the visualization of airspace configuration forecasts," in ICRAT 2010, 4th International Conference on Research in Air Transportation, 2010.

[28] K. D. Bilmoria, S. Banavar, G. B. Chatterji, K. S. Sheth, and S. Grabbe, "FACET: Future ATM concepts evaluation tool," 2000

[29] B. Girardet, L. Lapasset, D. Delahaye, C. Rabut, and Y. Brenier, "Generating optimal aircraft trajectories with respect to weather conditions," in ISIATM 2013, 2nd International Conference on Interdisciplinary Science for Innovative Air Traffic Management, 2013.

[30] L. Dray, A. Marzuoli, A. Evans, I. Laplace, and E. Féron, "Air Transportation and Multimodal, Collaborative Decision Making during Adverse Events," presented at the ATM seminar 2015, 11th USA/EUROPE Air Traffic Management R\&D Seminar, Lisboa, Portugal, 2015.

[31] S. Okwir and A. Correas, "Collaborative Decision Making $(\mathrm{CDM})$ in Airport Surface: Europe vs usa implementations, challenges and best practices," in 2014 Integrated Communications, Navigation and Surveillance Conference (ICNS) Conference Proceedings, 2014, pp. G2-1-G2-15.

[32] K. J. Vicente and J. Rasmussen, "Ecological interface design: Theoretical foundations," IEEE Transactions on systems, man, and cybernetics, vol. 22, pp. 589-606, 1992. 